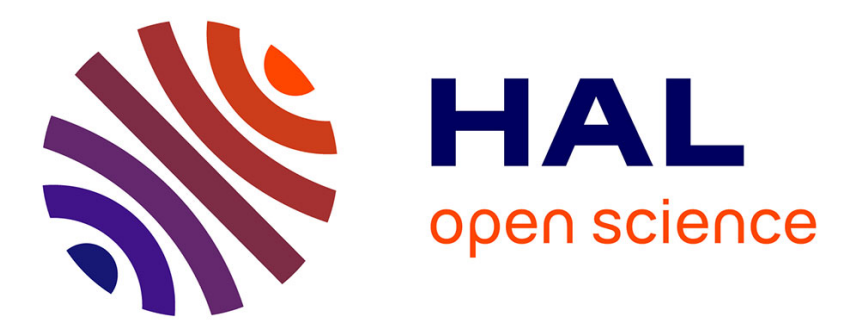

\title{
Survival curves of heated bacterial spores: effect of environmental factors on Weibull parameters
}

Olivier Couvert, Stéphane Gaillard, Nicolas Savy, Pierre Mafart, Ivan

Leguérinel

\section{- To cite this version:}

Olivier Couvert, Stéphane Gaillard, Nicolas Savy, Pierre Mafart, Ivan Leguérinel. Survival curves of heated bacterial spores: effect of environmental factors on Weibull parameters. International Journal of Food Microbiology, 2005, 101 (1), pp.73-81. 10.1016/j.ijfoodmicro.2004.10.048 . hal-00560873

\section{HAL Id: hal-00560873 \\ https://hal.univ-brest.fr/hal-00560873}

Submitted on 9 Jan 2012

HAL is a multi-disciplinary open access archive for the deposit and dissemination of scientific research documents, whether they are published or not. The documents may come from teaching and research institutions in France or abroad, or from public or private research centers.
L'archive ouverte pluridisciplinaire HAL, est destinée au dépôt et à la diffusion de documents scientifiques de niveau recherche, publiés ou non, émanant des établissements d'enseignement et de recherche français ou étrangers, des laboratoires publics ou privés. 
2 Effect of environmental factors on Weibull parameters

$4 \quad$ Olivier Couvert ${ }^{1}$, Stéphane Gaillard $^{1}$, Nicolas Savy $^{2}$, Pierre Mafart ${ }^{1}$,

$6 \quad{ }^{1}$ Laboratoire Universitaire de Microbiologie Appliquée de Quimper 2 rue de l'Université

$7 \quad 29334$ Quimper cedex, France Tel 33 2.98.90.02.27 Fax 33.2.98.64.03.71

$8{ }^{2}$ Institut de Recherche Mathématique de Rennes, Université de Rennes 1,

935042 Rennes Cedex, France.

*corresponding author e mail: guerinel@univ-brest.fr

Abstract

The classical D value of first order kinetic is not suitable for quantifying bacterial heat resistance for non-log linear survival curves. One simple model derived from the Weibull cumulative function describes non-log linear kinetics of micro-organisms. The influences of environmental factors on Weibull model parameters, shape parameter "p" and scale parameter “ $\delta$ ", were studied. This paper points out structural correlation between these two parameters. The environmental heating and recovery conditions do not present clear and regular influence on the shape parameter "p" and cannot be described by any model. On the opposite, the scale parameter " $\delta$ " depends on heating temperature and heating and recovery medium $\mathrm{pH}$. The

21 models established to quantify these influences on the classical "D" values could be applied to this parameter " $\delta$ ". The slight influence of the shape parameter p variation on the goodness of 
23 fit of these models can be neglected and the simplified Weibull model with a constant p-value

24 for given microbial population can be applied for canning process calculations.

25 Key words:

26 Weibull distribution, Heat treatment $\mathrm{pH}$, recovery medium $\mathrm{pH}$ 


\section{Introduction}

The first order kinetic model describing inactivation of micro-organisms is generally attributed to Madsen and Nyman (1907). The studies of Chick (1910), Esty and Meyer (1922), Esty and Williams 1924 on vegetative cells had confirmed this equation:

$$
\mathrm{N}=\mathrm{N}_{0} \mathrm{e}^{-\mathrm{kt}} \mathrm{Eq} 1
$$

where $\mathrm{N}_{0}$ is the initial number of cells, $\mathrm{N}$ the number of surviving cells after a duration of heat treatment $\mathrm{t}$ and $\mathrm{k}$ is the first order parameter .

In 1943 Katzin et al. defined the decimal reduction time that Ball and Olson (1957) symbolized by the letter D. Thus the model appears on the familiar form:

$$
\log \mathrm{N}=\log \mathrm{N}_{0}-\frac{\mathrm{t}}{\mathrm{D}} \mathrm{Eq} 2
$$

In this model the classical D value presents a simple biological significance: time that leads to a ten fold reduction of surviving population, and is easily estimated from a simple linear regression. This concept still governs canning process calculation.

However in many cases the survival curves of heated bacteria do not present a log linear relation: a concave or upward concavity of curves was frequently observed (Cerf, 1977).

So the bacterial heat resistance cannot be evaluated from the classical D value. Consequently, many authors proposed mechanistic or purely empirical models. (Kilsby et al., 2000; Rodriguez et al., 1988; Sapru et al., 1993; Shull et al., 1963; Xiong et al., 1999; Buchanan et al., 1997; Cole et al., 1993; Geeraerd et al., 2000; Linton et al., 1995; Whiting, 1993). These models show good accuracy either over parameterized (mechanistic models) or have parameters without any physical or biological significance (empirical models). Moreover the complexity of these models hinder their application in heat treatment process calculation.

Other authors who considered the survival curve as a cumulative form of temporary distribution of lethality event distribution, presented a probabilistic approach ( Cunha et al., 
51 1998; Fernandez et al., 1999; Peleg and Cole, 1998 Peleg, 2000; Mafart et al., 2002). The

52 Weibull frequency distribution model (Eq3) involved to describe the time to failure in 53 mechanical system was applied to bacterial death time.

$54 \quad f(t)=\frac{\beta}{\alpha}\left(\frac{t}{\alpha}\right)^{\beta-1} \times \exp \left(-\left(\frac{t}{\alpha}\right)^{\beta}\right) \mathrm{Eq} 3$

55 The $\beta$ parameter has a marked effect on the failure rate of the Weibull distribution (Fig 1a). 56 According to the $\beta$ value, the distribution corresponds to a normal law $(\beta=2)$, an exponential 57 law $(\beta=1)$ or an asymptotic law $(\beta<1)$.

58 A change of the scale parameter $\alpha$, time unit, has the same effect on the distribution than a 59 change of the abscise scale (Fig 1b). If $\alpha$ increases, the distribution gets stretched out the right 60 and its height decreases while maintaining its shape.

61 The cumulative distribution Weibull function is

$62 \quad F(t)=\exp \left(-\left(\frac{t}{\alpha}\right)^{\beta}\right)$ Eq 4

63 or applied to survival kinetics curves

$64 \ln S(t)=-\left(\frac{t}{\alpha}\right)^{\beta} \mathrm{Eq} 5$

where $\mathrm{S}(\mathrm{t})$ is the ratio $\mathrm{N} / \mathrm{N}_{0}$ at $\mathrm{t}$ time, $\alpha$ and $\beta$ are the two parameters of the Weibull 66 probability density function.

67 Figures $1 \mathrm{c}$ and $1 \mathrm{~d}$ show the influence of these two parameters evolution on the cumulative 68 distribution Weibull function curves. $\beta<1$ corresponds to concave upward survival curves, $69 \beta>1$ to concave downward curves and $\beta$ equal 1 to a straight line. The evolution of $\alpha$ value 70 modifies the slope but does not affect the curve shapes. Different forms of this model were 71 presented in literature, however the decimal logarithm form (Eq 6) which is close to Eq 2, 
Boekel, 2002)

74

$$
\log \mathrm{N}=\log \mathrm{N}_{0}-\left(\frac{\mathrm{t}}{\delta}\right)^{\mathrm{p}}(\mathrm{Eq} 6)
$$

where $\delta$ is to the first reduction time that leads a ten fold reduction of survival population, and $\mathrm{p}$ the shape parameter $\beta$. For the traditional case where the survival curve, originated from a first order, is linear p equal 1 and the $\delta$ parameter correspond to the classical D value.

This simple and robust model can be regarded as an extension of the conventional first order equation. Like on D value, the influence of heating temperature on the $\delta$ value leads a log linear relationship. The classical z value can be evaluated (Mafart et al., 2002; Van Boekel, 2002) and a modified Bigelow method can be used to optimize the heat treatment for a target reduction ratio (Mafart et al., 2002).

Among environmental factors other than heating temperature, which affect the heat resistance of bacteria, the $\mathrm{pH}$ of the heating medium and the $\mathrm{pH}$ of the recovery medium ( $\left.\mathrm{pH}^{\prime}\right)$ present a prominent importance. Couvert (1999) has developed an extended Bigelow model to describe both effects of heating and recovery medium $\mathrm{pH}$ on the apparent bacterial spore heat resistance.

$$
\log \mathrm{D}=\log \mathrm{D} *-\frac{\mathrm{T}-\mathrm{T}^{*}}{\mathrm{z}_{\mathrm{T}}}-\left|\frac{\mathrm{pH}-\mathrm{pH} *}{\mathrm{z}_{\mathrm{pH}}}\right|-\left(\frac{\mathrm{pH}^{\prime}-\mathrm{pH}^{\prime *}}{\mathrm{z}_{\mathrm{pH}}^{\prime} 90}\right)^{2} \quad \mathrm{Eq} 7
$$

Where $\mathrm{pH}^{*}$ and $\mathrm{pH}^{*}$ are the reference heat treatment and recovery medium $\mathrm{pH}$ fixed to $7 . \mathrm{z}_{\mathrm{pH}}$ is a distance of $\mathrm{pH}$ from $\mathrm{pH}^{*}$, which leads to a ten fold reduction D-value. $\mathrm{z}_{\mathrm{pH}}$ quantifies the heat medium $\mathrm{pH}$ influence on bacterial heat resistance. $\mathrm{z}_{\mathrm{pH}}^{\prime}$ is a distance of $\mathrm{pH}^{\prime}$ from $\mathrm{pH}^{\prime}$ *, which leads a ten fold reduction apparent D-value. $\mathrm{z}_{\mathrm{pH}}{ }_{\mathrm{H}}$ characterizes the influence of the $\mathrm{pH}$ 
on the recovery of the micro-organism after a heat treatment. $D^{*}$ is the calculated $\mathrm{D}$ value corresponding to $\mathrm{pH}^{*}$ and $\mathrm{pH}^{*}$ conditions. Like the Bigelow model, Couvert's model (Eq7) was suitable for the calculation of $\delta$ values as well as for those of $\mathrm{D}$ values. However the influence of heating temperature on the $\mathrm{p}$ value is not clear and variable according to several authors (Fernandez et al., 1999; Peleg and Cole, 2000; Mafart et al., 2002; Van Boekel, 2002). The aims of this paper are to bring arguments to estimate a single $\mathrm{p}$ value from a set of survival kinetics, whatever the heating temperature or heating and recovery medium $\mathrm{pH}$ for bacterial strain at a given physiology state.

\section{Material and methods}

\subsection{Microorganism and spore production}

Bacillus pumilus A40 was obtained and isolated from ingredient in a food canning industry. Spores were kept in distilled water at $4^{\circ} \mathrm{C}$.

Cells were pre-cultivated at $37^{\circ} \mathrm{C}$ for 24 hours in Brain Heart Infusion (Difco 0037). The preculture was used to inoculate nutrient agar (Biokar Diagnostics, Beauvais / France) supplemented with salt $\left(\mathrm{MnSO}_{4} 40 \mathrm{mg} \mathrm{l}^{-1}\right.$ and $\mathrm{CaCl}_{2} 100 \mathrm{mgl}^{-1)}$. Plates were incubated at $37^{\circ} \mathrm{C}$ for 5 days. Spores were then collected by scrapping the surface of the agar, suspended in sterile distilled water and washed three times by centrifugation (10000xg for $15 \mathrm{~min}$ ) (Bioblock Scientific, model Sigma 3K30). The pellet was resuspended in $5 \mathrm{ml}$ distilled water and $5 \mathrm{ml}$ ethanol. The obtained suspension was kept at $4^{\circ} \mathrm{C}$ for 12 hours in order to reduce the number of vegetative non sporulated bacteria, and washed again three times by centrifugation. The final suspension (about $10^{10}$ spores $\mathrm{ml}^{-1}$ ), containing more than $99 \%$ refractive spores and no visible vegetative cells, was finally distributed in sterile Eppendorf microtubes and kept at $4^{\circ} \mathrm{C}$ 
122 2.2. Thermal treatment of spore suspension and recovery conditions

124 Heating media were tryptone salt broth ( $10 \mathrm{~g} / \mathrm{l}$ tryptone, $10 \mathrm{~g} / \mathrm{l} \mathrm{NaCl}$ (Biokar)) for different $\mathrm{pH}$ 125 adjusted with addition of $1 \mathrm{M} \mathrm{H}_{2} \mathrm{SO}_{4}$, media were sterilized by filtration through $0.22 \mu \mathrm{m}$ 126 porosity filter. $30 \mu \mathrm{l}$ of spore suspension was diluted in $3 \mathrm{ml}$ of these media. Capillary tubes of $127200 \mu \mathrm{l}$ (vitrex) were filled with $100 \mu \mathrm{l}$ of sample and submitted to a thermal treatment in a 128 thermostated water bath. After heating, the tubes were cooled in water/ice bath. After rising, 129 the ends were flamed with ethanol. The capillary tubes were broken at both ends and their 130 contents poured into a tube containing $9 \mathrm{ml}$ sterile tryptone salt broth (Biokar Diagnostics) by 131 rinsing with $1 \mathrm{ml}$ tryptone salt broth.

132 Viable spores were counted by duplicate plating in nutrient agar for different $\mathrm{pH}(10 \mathrm{~g}$ 133 tryptone, 5g meat extract, $5 \mathrm{~g}$ sodium chloride, $15 \mathrm{~g}$ agar for 1000ml water)(Biokar

134 Diagnostic). The $\mathrm{pH}$ was adjusted with $\mathrm{H}_{2} \mathrm{SO}_{4}$ prior to autoclaving at $121^{\circ} \mathrm{C}$ for 15 min, the $135 \mathrm{pH}$ value was controlled after autoclaving.

\subsection{Experimental design}

139 To determine the thermal kinetic parameters at least ten samples were counted on nutrient 140 agar plates. For the longest heating time no colonies should be observed to detect possible 141 sigmoid curves.

142 Monofactorial designs were used to evaluate the influence of heating temperature, heating and

143 recovery medium $\mathrm{pH}$. The heating temperatures investigated were $89,92,95,98,101$ and

$144104^{\circ} \mathrm{C}$ (for heating and recovery media $\mathrm{pH}$ equal to 7 ), heating media $\mathrm{pH}$ were $7,6.1,5.8,5.2$, 
$1455.15,5.1,4.7$ and recovery media $\mathrm{pH}^{\prime}$ were $7,6.52,6.26,6.04,5.82,5.55$ and 5.27 (for

146 temperature $95^{\circ} \mathrm{C}$ ).

147

\subsection{Fitting parameters and region confidence determination}

149

150 To estimate Weibull parameters two fitting ways were realized. On the one hand, three 151 parameters $\log \mathrm{N}_{0}, \delta$ and $\mathrm{p}$ were estimated from each kinetic. On the other hand, two 152 parameters $\log \mathrm{N}_{0}$ and $\delta$ were estimated from each kinetic with only one p value evaluated 153 from the whole set of kinetics.

154 Couvert's model parameters (Eq 7) were estimated from these two sets of $\delta$ estimates. The 155 parameter values and their associated confidence interval were fitted by using a non-linear 156 module ("nlinfit" and "nlparci" Matlab 6.1, The Mathworks). "nlparci" function used to 157 evaluate confidence interval at $95 \%$ is based on the asymptotic normal distribution for the 158 parameter estimates ( Bates and Watts. 1988) On the one hand, $\mathrm{p}$ value was estimated from 159 each set of data, and on the other hand, single $\mathrm{p}$ value was evaluated from the whole set of 160 curves. To appreciate the accuracy on the non linear models used in this study $\mathrm{F}$ test and 161 associated probability $\mathrm{p}$ were carried out.

162

3 Results and discussion

164

\subsection{Independence of Weibull model parameters}

166

167 One of the main questions to study in any regression is to check the independence of model 168 parameters. The shape of the joint confidence region determined by using Lobry et al. (1991)

169 method leads to detect possible structural correlation between model parameters. According 
to Beale (1960), a vector of parameter model $\Theta$ is in the confidence regions if probability $\alpha$ verifies the inequation:

$$
S S D_{\Theta} \leq S S D_{\min }\left(1+\frac{p}{n-p} F_{p, n-p, \alpha}\right) \text { Eq } 8
$$

$\mathrm{n}$ number of data, $\mathrm{p}$ number of parameters, F Fisher value for $\alpha$ at $\mathrm{p}$ and $\mathrm{n}-\mathrm{p}$ degrees of freedom. 10000 vectors $\Theta$ were calculated to define the joint confidence region where dimension number is the parameter number. Figure 2 shows the projections of confidence region projected on three orthogonal planes. The strength shape of the projections and the high correlation coefficient associated characterize a structural correlation between model parameters. Three Weibull model parameters were estimated from each kinetic data and correlation coefficients were determined from the evaluated confidence region, for the 18 environmental conditions studied (Table 1) confirms this structural correlation between parameters for all kinetics. Thus, Weibull model parameters $\left(\log \mathrm{N}_{0}, \delta\right.$ and $\left.\mathrm{p}\right)$ are dependent: an error on $\delta$ will be balanced by an error on $\mathrm{p}$ in the same way. Finally, a single $\mathrm{p}$ value estimated from the whole set of kinetics eliminates the structural correlation between $\delta$ and $p$ parameters as well as $\log \mathrm{N}$ and p parameters (Table 1) and decreases the structural correlation between $\log \mathrm{N}$ and $\delta$. The Weibull model parameters become independent.

\section{Influence of environmental factors on p-value}

For each Bacillus pumilus survival curve, the shape parameter $\mathrm{p}$ values were estimated. Figure 3 suggests that the environmental heating and recovery conditions slightly influence the p values. This observation is in agreement with Fernandez et al. (2002) data concerning the influence of heating temperature and heating $\mathrm{pH}$ medium on the $\mathrm{p}$ values for Bacillus cereus spores. Van Boekel (2002) used bibliography data to study the influence of heating 
temperature on the shape $(\mathrm{p})$ and scale $(\delta)$ Weibull model parameter for different vegetative bacteria and yeast species survival kinetics. In most cases the shape parameter is clearly independent of heating temperature, however, in some cases, dependencies appear significantly. Constant $\mathrm{p}$ value means that the Weibull probability density function curves presents the same shape. Applied to the density probability distribution of inactivation death time, a single $\mathrm{p}$ value leads us to consider that whatever the environmental condition, the least resistant bacteria die first and the most resistant bacteria are the last to die while maintaining proportion. For a given microbial population, at the same physiological state, if the population proportion is independent of heating and recovery conditions, the Weibull model shape parameter $\mathrm{p}$ value should be constant. To estimate a single p value, Fernandez et al. (2002) determines average of shape parameter determined from the different kinetics. Then, for each kinetic, the scale parameter was re-estimated from set of data with fixed p value. However, it is preferable to evaluate both single shape and scale parameter by non linear least square 211 reduction for the whole set of data. Choosing the average value to evaluate a single $\mathrm{p}$ value is 212 not suitable because the number of data in each kinetic is not equal, each kinetic have not the 213 same weight on the $\mathrm{p}$ value evaluation. On the other hand, evaluating $\mathrm{p}$ value by estimating 214 process on the whole set of data consider that each data have the same weight in the $\mathrm{p}$ value 215 evaluation.

\subsection{Influence of environmental factors on $\delta$-value}

219 To evaluate the influence of fixed / free $\mathrm{p}$ value on the scale parameter, the corresponding $\delta$ 220 values were compared. (Table 2). The results show clearly that the accuracy of the Weibull 221 model, characterized by $\mathrm{F}$ test and associated probability, is lower when a single $\mathrm{p}$ value is 222 evaluated. However the $\delta$ value confidence intervals were reduced, and $\delta$ parameter could be 
described by the Bigelow model and the classical $z_{T}$ value can be evaluated (Table 3$)\left(z_{T}\right.$ is

224 the distance of temperature from $\mathrm{T}^{*}$ which leads to a ten fold reduction of the first decimal

225 reduction time $\delta$ ). Whatever the $\delta$ calculation procedure, no significant difference appears.

226 Van Boekel (2002) has alike applied the Bigelow model to assess the heating temperature

227 influence on the scale parameter values $\delta$, however the Arrhenius model as well can be 228 applied (Fernandez et al., 2002).

229 Like the classical D value, the scale parameter $\delta$ decreases with heating and recovery medium 230 pH (Mafart et al., 1998; Couvert et al., 1999; Couvert ,2002). Couvert's model, (Eq 7) 231 including the dependence temperature and heating and recovery medium $\mathrm{pH}$, was fitted on the $232 \delta$ values evaluated with the two calculation methods. Table 3 presents the parameter estimated 233 and Figures 4 a \& b compares observed and calculated values, and show a slight higher 234 accuracy of Couvert's model when the $\delta$ values were evaluated with single p value.

235 For the Bacillus cereus strain, Fernandez et al. (2002), following a full factorial design, four 236 levels of heating temperature and $\mathrm{pH}$ medium, evaluated Weibull scale parameter $\delta$. The 237 goodness of fit of Couvert's model on these data (Figure $5 \&$ Table 4) confirms the adequacy 238 of this model on the scale parameter estimated with a single shape parameter value $\mathrm{p}$.

239 These results confirm that single $\mathrm{p}$ value evaluated from a set of survival kinetics is sufficient 240 to describe the survival kinetics and the effect of external factors on bacterial heat resistance. 241 Furthermore, the evolution of $\mathrm{p}$ values, determined for each kinetics according to 242 environmental conditions, are too irregular to be described by any constant model (Van 243 Boekell 2002)

244 The Weibull model is suitable for describing log linear, or not, heat survival curves. However, 245 a simplification of this model consisting in getting a single overall estimation of $\mathrm{p}$-value per 246 strain, regardless of environmental conditions of heat treatment and recovery, seems to be enough for bacterial food predictive modeling and canning process calculation (Mafart et al., 
248 2002). Moreover, despite a slight loss of goodness of fit, this modification leads to an 249 improvement of the robustness of the model. However the cell physiology states seem to 250 influence the density function; as a result, the $\mathrm{p}$ values are likely to change. Further works 251 should be realized to assess the influence of spore age and environmental sporulation or 252 germination conditions on the Weibull shape parameter value.

253 As expected, the secondary model developed to describe the heating and recovery 254 environmental influence on the classical D values remains suitable for $\delta$ value estimates. 255 256 257 
260 Ball, C. O., and Olson, F. C. W., 1957. "Sterilization in food technology Theory, practice and 261 calculation." McGraw-Hill Book Compagny, inc.

262 Bates, D.M. and Watts, D.G., 1988 “Nonlinear Regression Analysis and Its Applications”. 263 John Wiley \& Sons, NY.

264 Beale, E.M., 1960 Confidence region in non-linear estimation. Journal of Royal Statistic 265 Society B22, 41-88.

266 Buchanan, R. L., Golden, M. A., and Phillips, J. G., 1997. Expanded models for the non267 thermal inactivation of Listeria monocytogenes. Journal of Applied Microbiology 82, 567268577.

269 Cerf, O., 1977. Tailing of survival curves of bacterial spores, a review. Journal of Applied $270 \quad$ Bacteriology 42, 1-19

271 Chick, H., 1910. The process of disinfection by chemical agencies and hot water. Journal of 272 Hygiene, Cambridge 10, 237-286.

273 Cole, M. B., Davies, K. W., Munro, G., Holyoak, C. D., and Kilsby, D. C., 1993. A vitalistic 274 model to describe the thermal inactivation of Listeria monocytogenes. Journal of Industrial 275 Microbiology 12, 232-239.

276 Couvert, O., Leguérinel, I., and Mafart, P., 1999. Modelling the overall effect of pH on the 277 apparent heat resistance of Bacillus cereus spores. International Journal of Food Microbiology $278 \quad 49,57-62$.

279 Couvert, O., 2002. Prise en compte de l'influence du pH dans l'optimisation des traitements 280 thermiques. These de l'Université de Bretagne Occidentale. 
281 Cunhan, L. M., Oliveira, F. A. R., and Oliveira, J. C., 1998. Optimal experimental design foe 282 estimating the kinetic parameters of processes described by the Weibull probability 283 distribution function. Journal of Food Engineering 37, 175-191.

284 Esty, J. R., and Meyer, K. F., 1922. The heat resistance of spores of B. botulinus and allied 285 anaerobes. Journal of Infectious Diseases 31, 650-663.

286 Esty, J. R., and Williams, C. C., 1924. Heat resistance studies. A new method for 287 determination of heat resistance of bacterial spores. Journal of Infectious Diseases 34, 516288528.

289 Fernandez, A., Collado, J., Cunhan, L. M., Ocio, M. J., and Martinez, A., 2002. Empirical 290 model building based on Weibull distribution to describe the joint effect of $\mathrm{pH}$ and 291 temperature on the thermal resistance of Bacillus cereus in vegetable substrate. International 292 Journal of Food Microbiology 77, 147-153.

293 Fernandez, A., Salmeron, C., Fernandez, P. S., and Martinez, A., 1999. Application of a 294 frequency distribution model to describe the thermal inactivation of two strain of Bacillus 295 cereus. Food Science and Technology 10, 158-162.

296 Geeraerd, A. H., Herremans, C. H., and Impe, J. F. V., 2000. Structural model requirements to 297 describe microbial inactivation during a mild heat treatment. International Journal of Food 298 Microbiology 59, 185-209.

299 Katzin, L. I., Sandholzer, L. A., and Strong, M. E., 1943. Application of the decimal reduction 300 time principle to a study of the resistance of coliform bacteria to pasteurization. Journal of 301 Bacteriology 45, 256-272.

302 Kilsby, D. C., Davies, K. W., McClure, P. J., Adair, C., and Anderson, W. A., 2000. Bacterial 303 thermal death kinetics based on probability distributions: the heat destruction of Clostridium 304 botulinum and Salmonella bedford. Journal of Food Protection 63, 1197-1203. 
Linton, R. H., Carter, W. H., Pierson, M. D., and Hackney, C. R., 1995. Use of modified

306 Gompertz equation to model nonlinear survival curves for Listeria monocytogenes Scott A. 307 Journal of Food Protection 58, 946-954.

308 Lobry, J.R., Rosso, L., Flandrois, J.P., 1991.A FORTRAN subroutine for the determination of 309 parameter confidence limits in non-linear model. Binary 3, 86-93.

310 Madsen, T., and Nyman, M. 1907. Zur theorie der desinfektion. Zeitschrift für Hygiene und 311 Infectionskrankheiten 57, 388-404.

312 Mafart, P., Couvert, O., Gaillard, S., and Leguerinel, I., 2002. On calculating sterility in 313 thermal preservation methods: application of Weilbull frequency distribution model. 314 International Journal of Food Microbiology 72, 107-113.

315 Peleg, M., and Cole, M. B., 1998. Reinterpretation of microbial survival curves. Critical 316 Reviews in Food Science 38, 353-380.

317 Peleg, M., and Cole, M. B., 2000. Estimating the survival of Clostridium botulinum spores 318 during heat treatment. Journal of Food Protection 63, 190-195.

319 Rodriguez, A. C., Smerage, G. H., Teixeira, A. A., and Busta, F. F., 1988. Kinetic effect of 320 lethal temperature on population dynamics of bacterial spores. Transaction of the American 321 Society of Agricultural Engineers 31, 1594-1601, 1606.

322 Sapru, V., Smerage, G. H., Teixeira, A. A., and Lindsay, J. A., 1993. Comparaison of 323 predictive model for bacterial spore population resources to sterilization temperature. Journal 324 of Food Science 58, 223-228.

325 Shull, J. J., Cargo, G. T., and Ernst, R. R., 1963. Kinetics of heat activation and of thermal 326 death of bacterial spores. Applied Microbiology, 485-487.

327 van Boekel, M. A. J. S., 2002. On the use of the Weilbull model to describe thermal 328 inactivation of microbial vegetative cells. International Journal of Food Microbiology 74, $329 \quad 139-159$. 
330 Whiting, R. C., 1993. Modeling bacterial survival in unfavorable environments. Journal of 331 Industrial Microbiology 12, 240-246.

332 Xiong, R., Xie, G., Edmondson, A. E., and Sheard, M. A., 1999. A mathematical model for 333 bacterial inactivation. International Journal of Food Microbiology 49, 45-55. 
334 Table legend

336 Table 1: Correlation coefficients between Weibull model parameters evaluated from the 337 evaluated joint confidence for the 18 environmental studied conditions.

340 Table 2:

341 Weibull model parameters definite with associated $\mathrm{p}$ value determined for each kinetic for 342 one part, for the other with single $\mathrm{p}$ value evaluated for the whole set of kinetics for Bacillus 343 pumilus $\mathrm{A} 40$

$345 \quad$ Table 3

346 Couvert's model parameters fitted on $\log \delta$ values evaluated with multiple $\mathrm{p}$ values on the one 347 hand, with single $\mathrm{p}$ values for Bacillus pumilus A40 on the other. The method used to 348 compute the $95 \%$ confidence intervals is based on an "asymptotic normal distribution for the 349 parameter estimate". (Bates and Watts 1988)

$351 \quad$ Table 4

352 Couvert's model parameters fitted on $\log \delta$ values for Bacillus cereus INRA TZ 415 353 (Fernandez et al., 2002) 
$356 \quad$ Figure legends

$358 \quad$ Figure 1

359 Simulated frequency distribution of critical inactivation time (Figures a and b) and microbial

360 survival curves (Figures $\mathrm{c}$ and $\mathrm{d}$ ) generated with the assumption that the heat resistance has a

361 Weibull distribution.

362 Figures a and c: $\alpha: 5, \beta: 3(-), 1(--), 0.5(\cdots)$, Figures $b$ and $d: \alpha: 3(-), 6(--), 9(\cdots), \beta: 3$

364 Figure 2

365 Projection of the confident region on three orthogonal planes, from Bacillus pumilus A40 data

366 (heating temperature : $95^{\circ} \mathrm{C}$, heating and recovery medium $\mathrm{pH}: 7$ )

$368 \quad$ Figure 3

369 Graph of the shape parameter $\mathrm{p}$ and $95 \%$ confidence interval associated as function of heating

370 temperature, treatment and recovery medium $\mathrm{pH}$ for Bacillus pumilus A40

372 Figures $4 \mathrm{a} \& \mathrm{~b}$

373 Comparison of calculated and observed $\log \delta$ values evaluated with multiple $\mathrm{p}$ values on the

374 one hand (Figure a: $\square$ ), with single p values on the other (Figure b: $\bigcirc$ )

375

$376 \quad$ Figure 5

377 Comparison of calculated and observed $\log \delta$ values. Couvert's model fitted from Fernandez 378 et al. (2002) data 


\begin{tabular}{|c|c|c|c|c|c|c|c|c|}
\hline \multirow[b]{2}{*}{$\mathrm{T}^{\circ}$} & \multirow[b]{2}{*}{$\mathrm{pH}$} & \multirow[b]{2}{*}{$\mathrm{pH}^{\prime}$} & \multicolumn{3}{|c|}{$\begin{array}{l}\mathrm{p} \text { values estimated from each set } \\
\text { of data }\end{array}$} & \multicolumn{3}{|c|}{$\begin{array}{c}\text { Overall } \mathrm{p} \text { value estimated from the } \\
\text { gathered sets of data }\end{array}$} \\
\hline & & & LogNo vs $\delta$ & $\log \mathrm{N}_{0}$ vs $\mathrm{p}$ & $\delta$ vs p & LogNo vs $\delta$ & $\log N_{0}$ vs $p$ & $\delta$ vs p \\
\hline 89 & 7 & 7 & -0.78 & -0.62 & 0.92 & -0.71 & 0.15 & -0.06 \\
\hline 92 & 7 & 7 & -0.81 & -0.63 & 0.89 & -0.74 & 0.12 & -0.06 \\
\hline 95 & 7 & 7 & -0.75 & -0.59 & 0.93 & -0.67 & 0.35 & -0.12 \\
\hline 98 & 7 & 7 & -0.81 & -0.64 & 0.9 & -0.74 & 0.17 & -0.08 \\
\hline 101 & 7 & 7 & -0.84 & -0.67 & 0.89 & -0.73 & 0.12 & -0.06 \\
\hline 104 & 7 & 7 & -0.82 & -0.67 & 0.93 & -0.71 & 0.26 & -0.09 \\
\hline 95 & 4.7 & 7 & -0.84 & -0.59 & 0.73 & -0.71 & 0.09 & -0.06 \\
\hline 95 & 5.1 & 7 & -0.9 & -0.74 & 0.88 & -0.77 & 0.15 & -0.08 \\
\hline 95 & 5.15 & 7 & -0.64 & -0.11 & 0.65 & -0.55 & 0.03 & -0.06 \\
\hline 95 & 5.2 & 7 & -0.86 & -0.7 & 0.92 & -0.65 & 0.21 & -0.08 \\
\hline 95 & 5.8 & 7 & -0.81 & -0.66 & 0.93 & -0.71 & 0.22 & -0.09 \\
\hline 95 & 6.1 & 7 & -0.82 & -0.52 & 0.77 & -0.82 & 0.12 & -0.05 \\
\hline 95 & 7 & 5.27 & -0.81 & -0.632 & 0.92 & -0.75 & 0.2 & -0.11 \\
\hline 95 & 7 & 5.55 & -0.85 & -0.71 & 0.91 & -0.77 & 0.16 & -0.06 \\
\hline 95 & 7 & 5.82 & -0.82 & -0.66 & 0.91 & -0.73 & 0.19 & -0.09 \\
\hline 95 & 7 & 6.04 & -0.87 & -0.74 & 0.9 & -0.74 & 0.15 & -0.10 \\
\hline 95 & 7 & 6.26 & -0.89 & -0.73 & 0.91 & -0.79 & 0.17 & -0.08 \\
\hline 95 & 7 & 6.52 & -0.86 & -0.72 & 0.89 & -0.72 & 0.10 & -0.07 \\
\hline
\end{tabular}

381

382

383

T1

384 


\begin{tabular}{|c|c|c|c|c|c|c|c|c|c|c|c|c|c|c|c|c|}
\hline \multirow[b]{2}{*}{$\mathrm{T}^{\circ}$} & \multirow[b]{2}{*}{$\mathrm{pHt}$} & \multirow[b]{2}{*}{$\mathrm{pHr}$} & \multicolumn{7}{|c|}{$\mathrm{p}$ values estimated from each set of data } & \multicolumn{7}{|c|}{ Single $p$ value for the whole set of kinetics } \\
\hline & & & $\log$ No & CI 95\% & delta & CI $95 \%$ & $\mathrm{p}$ & CI $95 \%$ & SSD & $\log$ No & CI $95 \%$ & delta & CI 95\% & $\mathrm{p}$ & CI $95 \%$ & SSD \\
\hline 89 & 7 & 7 & 4.09 & 0.18 & 49.14 & 4.83 & 2.87 & 0.76 & 0.012 & 4.27 & 0.18 & 42.01 & 3.23 & 1.96 & 0.14 & 0.172 \\
\hline 92 & 7 & 7 & 3.83 & 0.18 & 18.74 & 1.97 & 2.50 & 0.67 & 0.028 & 3.93 & 0.18 & 17.04 & 1.32 & 1.96 & 0.14 & 0.097 \\
\hline 95 & 7 & 7 & 4.20 & 0.12 & 9.25 & 0.86 & 2.03 & 0.32 & 0.149 & 4.22 & 0.12 & 9.06 & 0.51 & 1.96 & 0.14 & 0.153 \\
\hline 98 & 7 & 7 & 4.04 & 0.16 & 3.88 & 0.40 & 2.26 & 0.51 & 0.103 & 4.10 & 0.16 & 3.64 & 0.25 & 1.96 & 0.14 & 0.138 \\
\hline 101 & 7 & 7 & 3.93 & 0.18 & 1.51 & 0.18 & 2.19 & 0.62 & 0.070 & 3.98 & 0.16 & 1.44 & 0.11 & 1.96 & 0.14 & 0.084 \\
\hline 104 & 7 & 7 & 4.04 & 0.21 & 0.57 & 0.08 & 2.16 & 0.49 & 0.094 & 4.10 & 0.20 & 0.53 & 0.04 & 1.96 & 0.14 & 0.109 \\
\hline 95 & 4.7 & 7 & 3.66 & 0.26 & 1.91 & 0.56 & 1.10 & 0.36 & 0.543 & 3.35 & 0.17 & 2.70 & 0.23 & 1.96 & 0.14 & 0.689 \\
\hline 95 & 5.1 & 7 & 3.61 & 0.20 & 3.77 & 0.57 & 1.75 & 0.44 & 0.727 & 3.54 & 0.16 & 4.00 & 0.28 & 1.96 & 0.14 & 0.737 \\
\hline 95 & 5.15 & 7 & 4.20 & 0.29 & 1.66 & 1.19 & 0.59 & 0.46 & 0.008 & 3.84 & 0.28 & 3.22 & 0.47 & 1.96 & 0.14 & 0.352 \\
\hline 95 & 5.2 & 7 & 3.95 & 0.25 & 1.73 & 0.50 & 1.08 & 0.26 & 0.151 & 3.54 & 0.17 & 2.85 & 0.21 & 1.96 & 0.14 & 0.544 \\
\hline 95 & 5.8 & 7 & 4.03 & 0.22 & 3.67 & 0.61 & 1.78 & 0.42 & 0.051 & 3.96 & 0.18 & 3.90 & 0.28 & 1.96 & 0.14 & 0.066 \\
\hline 95 & 6.1 & 7 & 4.13 & 0.28 & 5.54 & 0.95 & 1.99 & 0.62 & 0.115 & 4.14 & 0.26 & 5.50 & 0.49 & 1.96 & 0.14 & 0.115 \\
\hline 95 & 7 & 5.27 & 3.89 & 0.24 & 1.12 & 0.25 & 1.32 & 0.32 & 0.280 & 3.60 & 0.17 & 1.48 & 0.11 & 1.96 & 0.14 & 0.563 \\
\hline 95 & 7 & 5.55 & 4.05 & 0.24 & 2.62 & 0.43 & 1.95 & 0.55 & 0.052 & 4.05 & 0.22 & 2.63 & 0.20 & 1.96 & 0.14 & 0.052 \\
\hline 95 & 7 & 5.82 & 3.79 & 0.16 & 3.72 & 0.35 & 2.60 & 0.61 & 0.084 & 3.93 & 0.16 & 3.28 & 0.23 & 1.96 & 0.14 & 0.209 \\
\hline 95 & 7 & 6.04 & 3.99 & 0.17 & 6.00 & 0.63 & 2.33 & 0.55 & 0.017 & 4.09 & 0.15 & 5.57 & 0.41 & 1.96 & 0.14 & 0.063 \\
\hline 95 & 7 & 6.26 & 3.83 & 0.20 & 4.54 & 0.60 & 1.95 & 0.45 & 0.177 & 3.82 & 0.17 & 4.55 & 0.31 & 1.96 & 0.14 & 0.177 \\
\hline 95 & 7 & 6.52 & 3.98 & 0.18 & 6.12 & 0.78 & 2.09 & 0.62 & 0.033 & 4.01 & 0.16 & 5.96 & 0.48 & 1.96 & 0.14 & 0.037 \\
\hline
\end{tabular}




\begin{tabular}{c|cc|cc}
\hline & \multicolumn{2}{|c|}{$\begin{array}{c}\text { p values determined } \\
\text { for each kinetic }\end{array}$} & \multicolumn{2}{|l}{$\begin{array}{l}\text { Single } \mathrm{p} \text { value for the } \\
\text { whole set of kinetics }\end{array}$} \\
\hline & Values & CI 95\% & Values & CI 95\% \\
\hline Log $\delta_{121.1} *$ & -2.38 & 0.44 & -2.36 & 0.26 \\
$\mathrm{z}_{\mathrm{T}}$ & 7.90 & 1.08 & 8.06 & 0.66 \\
$\mathrm{Z}_{\mathrm{pH}}$ & 3.37 & 0.77 & 5.09 & 1.03 \\
$\mathrm{z}_{\mathrm{pH}}^{\prime}$ & 1.92 & 0.23 & 2.06 & 0.17 \\
F test & 5.42 & & 5.57 & \\
$\mathrm{p}$ value & 0.0084 & & 0.0076 & \\
\hline
\end{tabular}

T3 


\begin{tabular}{c|c|c}
\hline & Values & CI 95\% \\
\hline $\log \delta_{121.1^{\circ} \mathrm{C}^{*}}$ & -3.48 & 0.21 \\
$\mathrm{Z}_{\mathrm{T}}$ & 7.71 & 0.34 \\
$\mathrm{Z}_{\mathrm{pH}}$ & 3.26 & 0.59 \\
F test & 7.46 & \\
$\mathrm{p}$ value & 0.0021 & \\
\hline
\end{tabular}

T4 

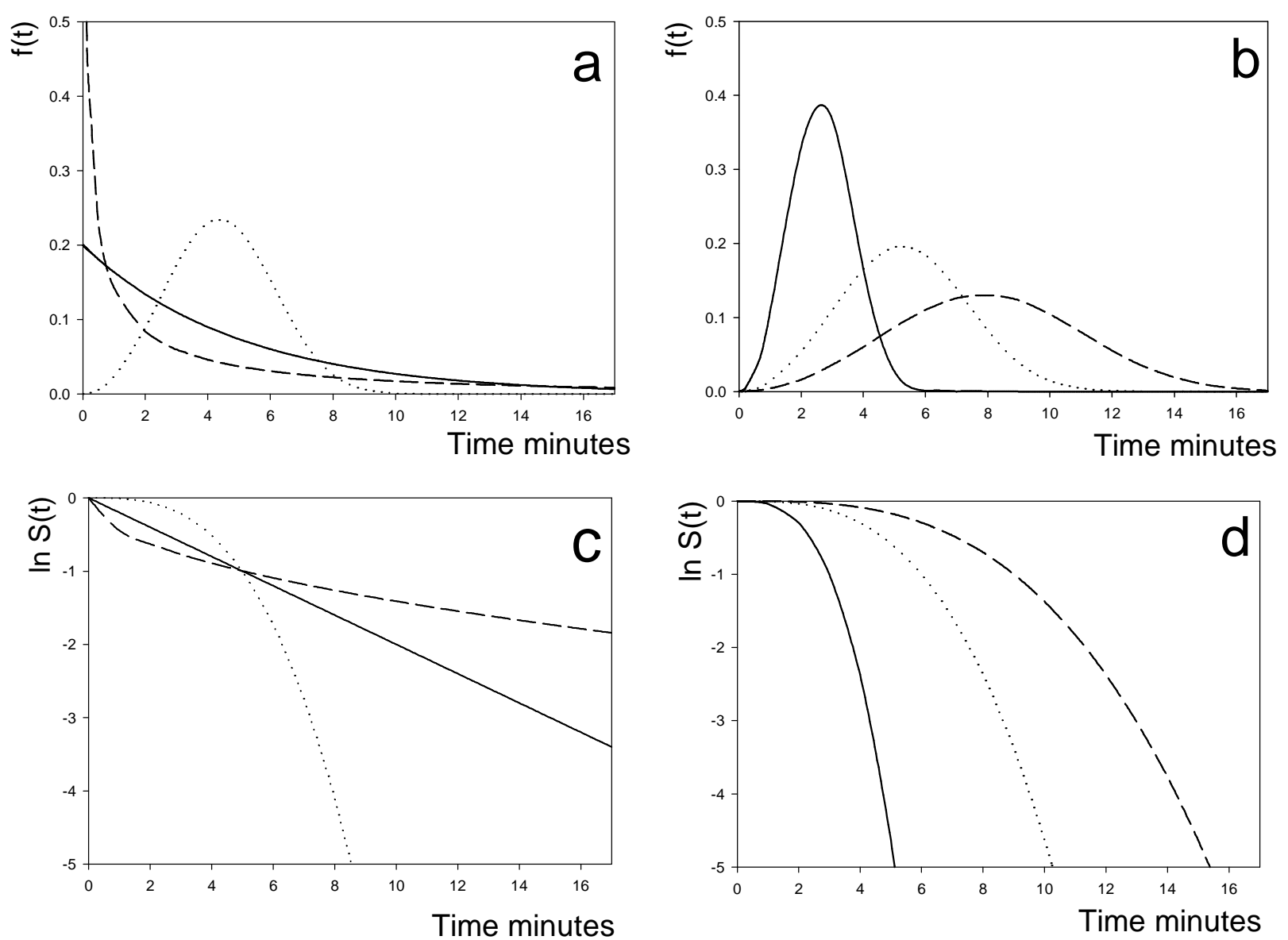

F1 

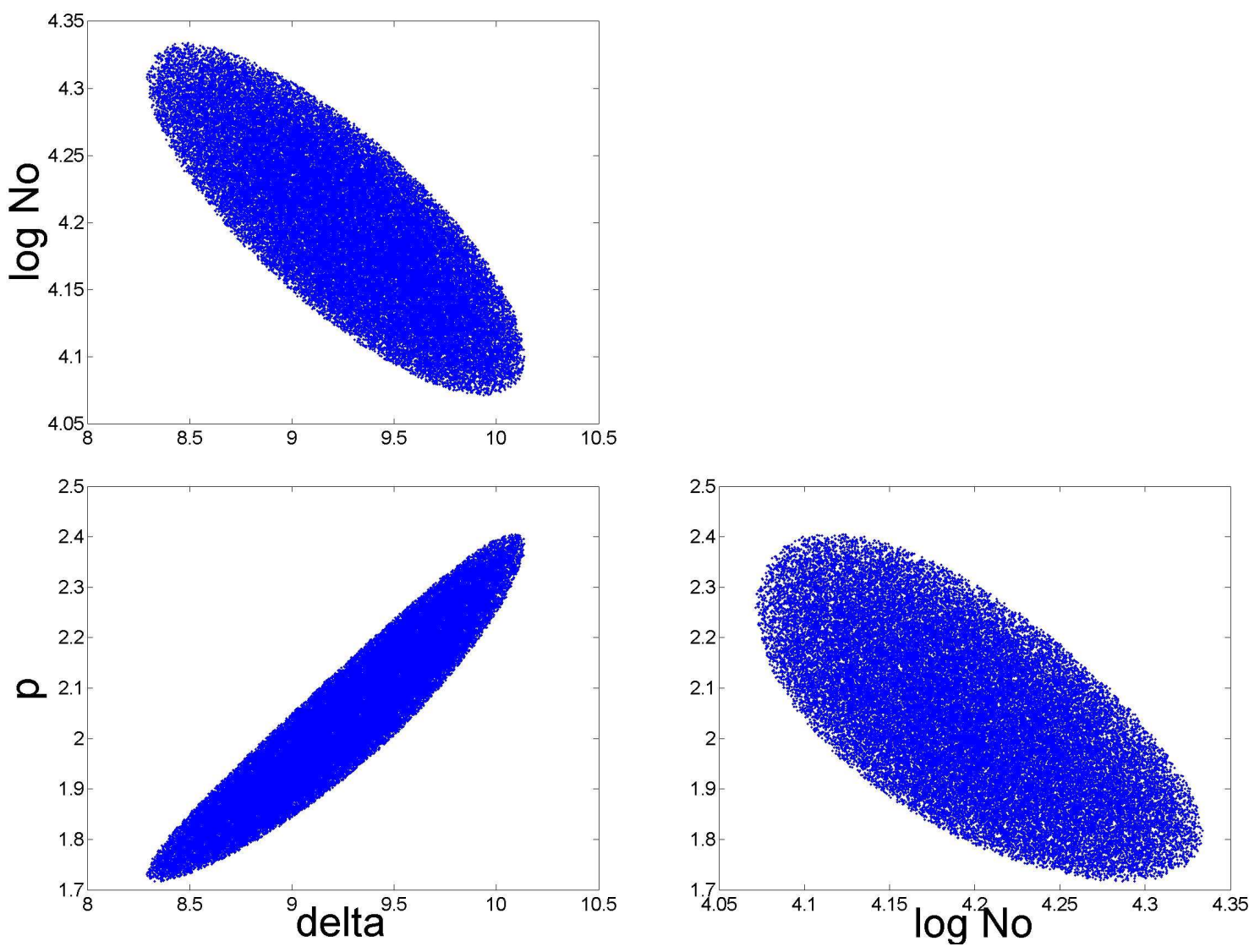

F2 


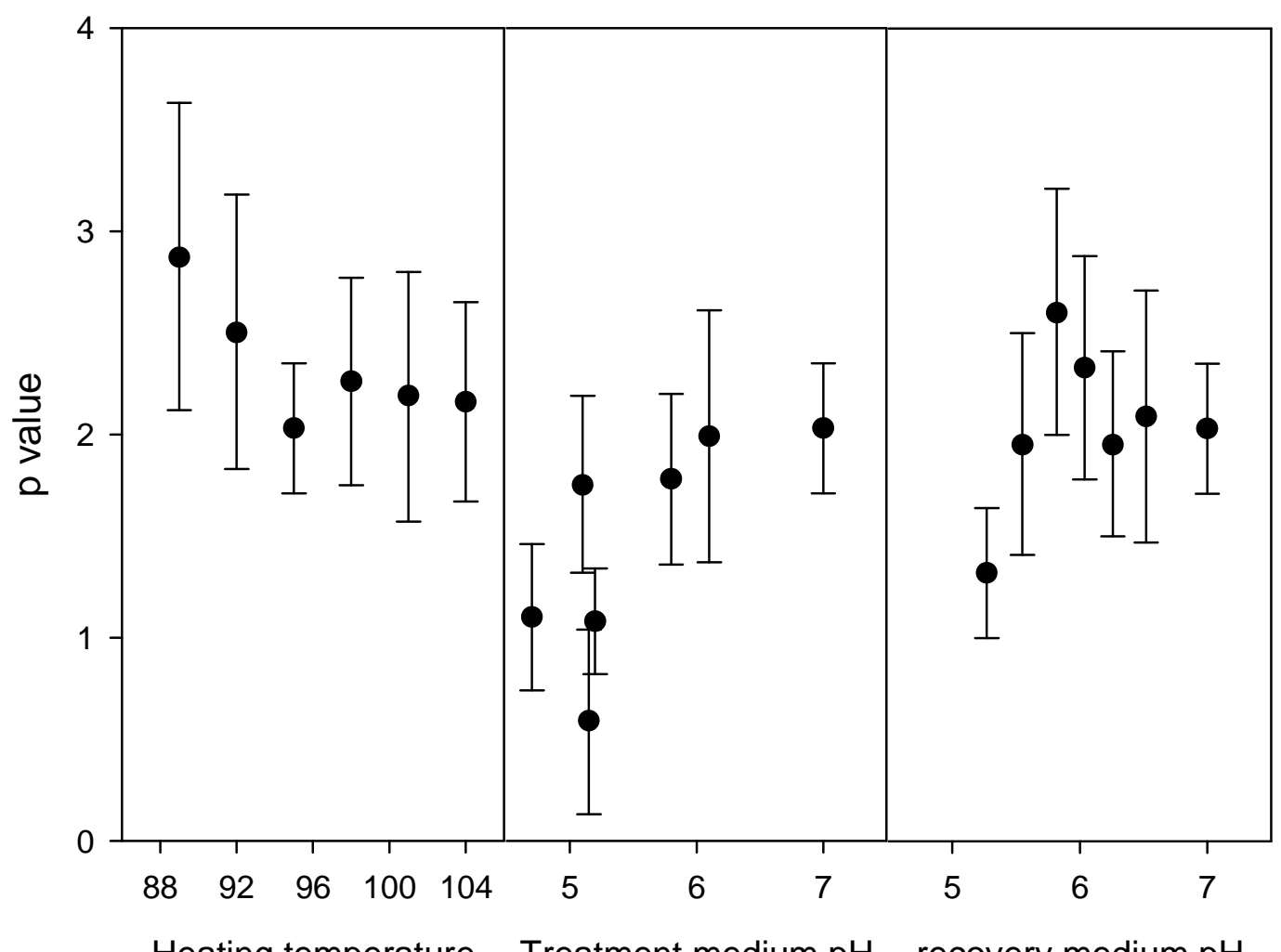

Heating temperature Treatment medium $\mathrm{pH}$ recovery medium $\mathrm{pH}$

F3 

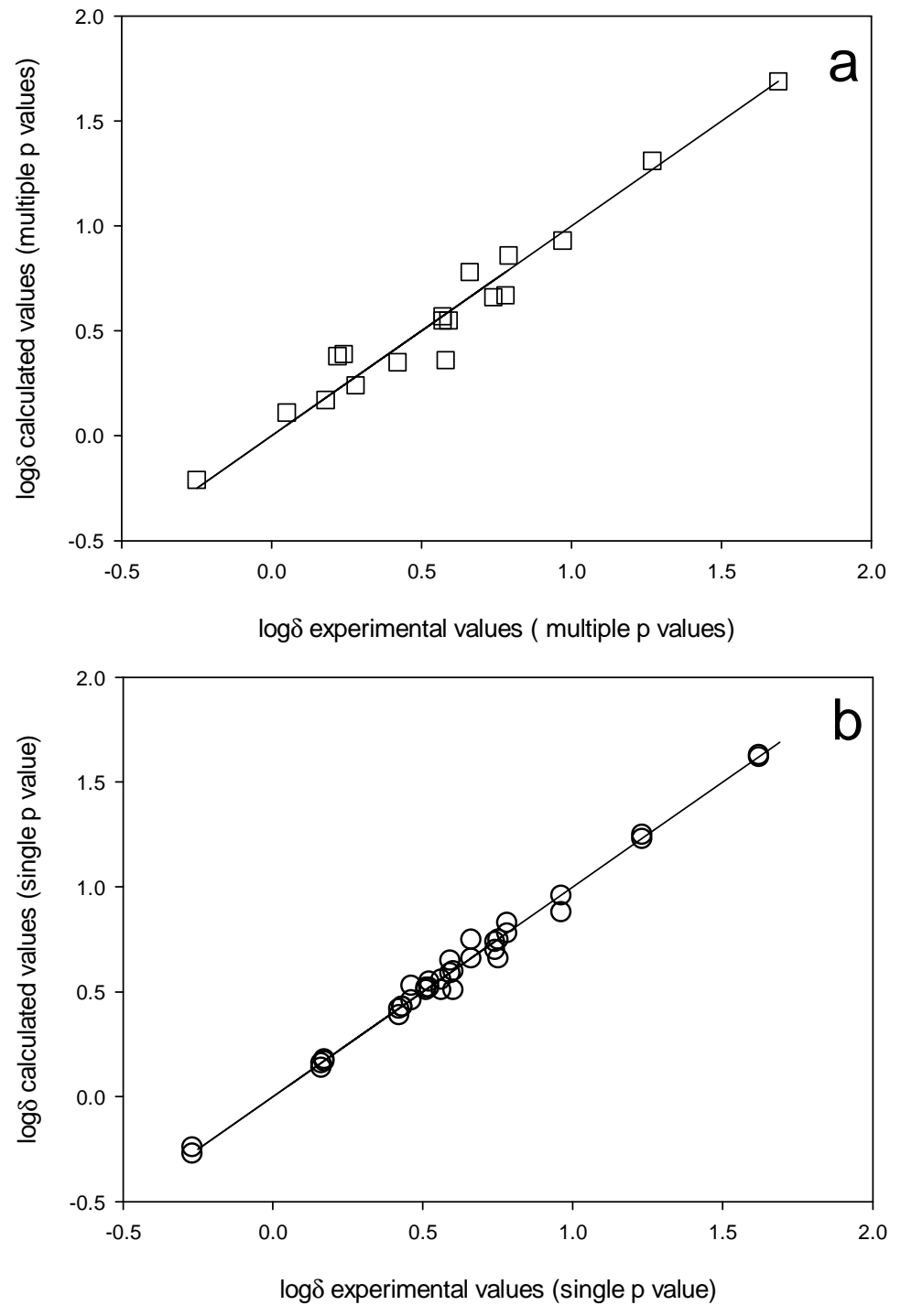

F4 a\&b 


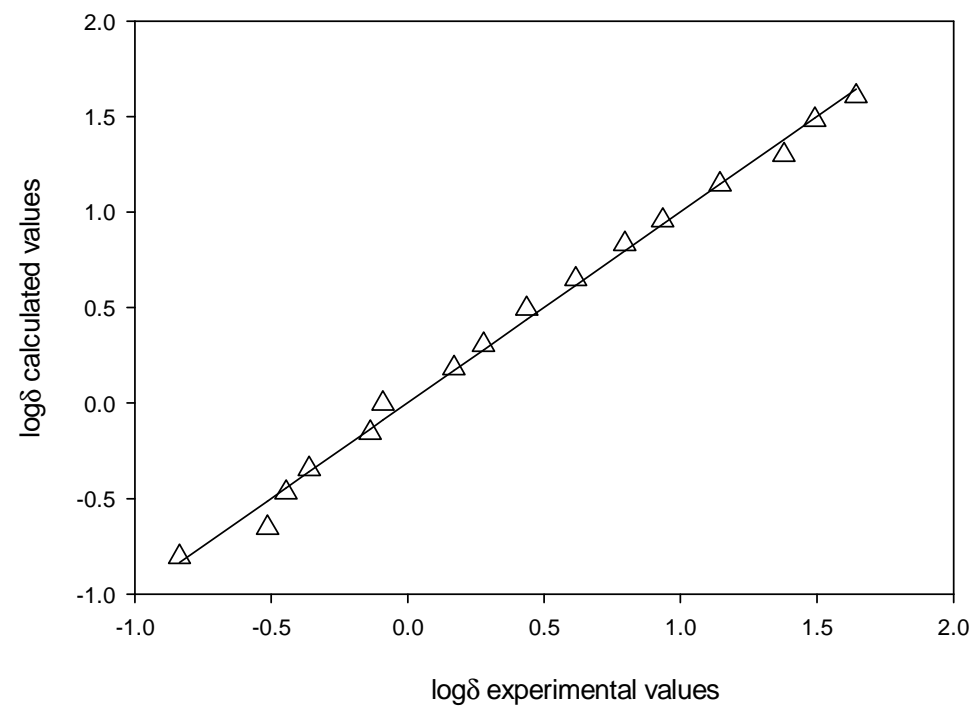

F5 
